\title{
Effects of Soil Geotechnical Properties on the Prediction of Optimal Dimensions of Restricted Reinforced Concrete Retaining Walls
}

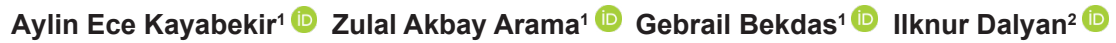 \\ ${ }^{1}$ Istanbul University-Cerrahpasa, Department of Civil Engineering, Istanbul, Turkey \\ ${ }^{2}$ Ministry of Interior Disaster and Emergency Management Presidency, Presidential of Earthquake Department, Ankara, Turkey
}

A B S T R AC T
The aim of this paper is to investigate the effects of soil properties associated with the pro-
ject requirements and environmental conditions, on the prediction of the design dimen-
sions of L-Shaped restricted reinforced concrete retaining walls by the use of optimization al-
gorithms. Numerous parametric analysis was conducted with Flower Pollination Algorithm
to examine the influence of soil geotechnical properties such as internal friction angle and
unit weight. The backfill soil, surrounding earth and foundation soil was modelled same
and assumed to be comprised of granular soils for modelling. Additionally, dual effects of ex-
ternal surcharge load application and excavation depth change was also analyzed against the
change of soil properties. As a result, the change of the retaining wall height and the founda-
tion base width has been discussed and the achievement of the cost-effective optimized sizing
of the system has been obtained. Finally, the design differences caused by the changes in soil
properties have been revealed and the practicalness of the use of the optimization algorithms
for the design of restricted type of retaining walls are shown.

Article History:

Received: 2020/03/24

Accepted: 2020/08/04

Online: $2020 / 09 / 30$

Correspondence to: Zülal Akbay Arama, Department of Civil Engineering, İstanbul University-Cerrahpaşa, Istanbul

Tel: +90 5532664880

E-Mail:zakbay@istanbul.edu.tr

Keywords:

Soil properties, Granular soils, L-Shaped retaining walls, Flower Pollination Algorithm, Optimization

\section{INTRODUCTION}

$\mathrm{R}$ einforced concrete retaining walls are the most preferred type of supporting structures that are constructed in order to resist lateral soil forces, especially activated due to the excavation works which the soil properties of the construction field cannot permit to hold the unbalanced soil mass with slopes. The shape and dimensions of the retaining wall system can be changed due to the project requirements, soil conditions, land ownership situation, infrastructure locations or environmental restrictions and it can be essential to build the sections of the wall with restrictions. The most known type of restricted reinforced concrete retaining walls is L-shaped type. L-shaped retaining walls (LSRW) are generally used for simple loading applications where the foundation length is extended only on the heel side of the wall. In this study, the mentioned L-Shaped type of reinforced concrete retaining walls was considered due to the preferability rather than other restricted type of supporting structures, according to the easiness of their construction works, the attainability of used materials and easiness of the mobilization of necessitated equipment for construction. The design process of the L-shaped retaining walls is being divided into two main steps as geotechnical and structural, similar with other non-restricted types. The control of stability requirements like sliding, overturning and bearing capacity adequateness, forms geotechnical part of the design process. But in order to perform stability calculations, pre-design has to be done generally according to the suggested sizing by well-accepted literature sources [1]. These pre-design methods envisage some restrictions to the structural sections of the wall and require to control if the stability necessities are supplemented. Trial and error method is used to check all proposed walls sizing at pre-design step and this recalculation loop leads loss of time [2].

Because not only the dimensions of the system will be the variants of the stability analysis of the first design stage, but also the geotechnical properties of soil conditions will change the necessitated sizing. The achievement of soil geotechnical properties is associated with the existence and interpretation of site investigations [3] But only for the construction of such simple structures like retaining walls, it is a common application all over 
the world not to do a soil survey to reduce expenses for the constructions or it will not be possible to obtain the essential parameters of the design directly with the performed tests. This condition directs designers to predict soil properties with the use of existing site investigations or to use envisaged upper and lower limits of defined values of soil properties by well-known sources of literature or to use empirical relationships $[1,4]$. In this context, the recalculation loop that is performed at the first step of the pre-design will be grown up and unexpected additional analysis will have to be done to find optimum sizing and cost balance. On behalf of to reduce these undesired additional analysis, it has been a significant factor to acquire proper geotechnical conditions representing the general characteristics of encompassing earth of the wall. At the second step of the design, it is being necessary for the wall sections to ensure enough shear and moment capacities and besides this the steel reinforcement must satisfy the proper code requirements to obtain structural design adequateness [5]. According to the pre-design procedure of the retaining walls, it will be hard to achieve the proper stability conditions against conceivable sizing for restricted type. Because the lack of one of the structural part of the wall leads to decrease the resisting forces [6]. In addition to this condition, necessitation to the extension of the wall heel is being arose. In such a case, the construction of L-Shaped walls caused to be chargeable. Therefore, new techniques are developed based on the advancing information and computer technologies to design retaining walls, considering the optimization of sizing and cost. Optimization methods are one of the technique that is used to design retaining walls effectively and nowadays there performed lots of studies to possess the most useful and cost-effective method to design wall systems [7, 8, 9, 10, $11,12]$. In this study, an optimization algorithm is used to predict optimum dimensions of L-Shaped retaining walls via minimum cost achievement against the change of soil geotechnical properties. The main theme of the study is to investigate the effects of the soil geotechnical properties individually and calculate the rate of influence on the de- sign with dual comparisons. For that purpose, the effects of the loading conditions and excavation depth is also taken into consideration as secondary influence parameters and 105000 different analysis cases are conducted with Flower Pollination Algorithm (FPA). In the analysis, the surrounding soil was assumed to be sandy and its shear strength is represented by the existence of only internal friction angle. The unit weight of soil was evaluated as other definer parameters of soil conditions to reach the minimum value of the safety of static limit equilibrium analysis. The results of the optimization analyses are estimated according to the change of foundation base width and thickness respectively. Consequently, it is shown that the internal friction angle is the most significant geotechnical parameter in the design of retaining walls for the fictionalized structures that are embedded in sandy soils. The width and thickness of the wall base are both affected by the change of internal friction and also the dual effect of the increase of the external load and excavation depth raises the wall sizing significantly. The unit weight of the soil affects the width of the base but has little influence on the thickness. The results of the optimization analyses show that L-Shaped restricted walls are not proper to resist lateral earth pressures which are caused because of bigger than 9 meters deep excavations.

\section{MATERIAL AND METHODS}

In the context of this study, reinforced concrete retaining walls are taken into consideration to designate the restrictions of construction that are caused by the variety of soil geotechnical properties against the achievement of quick and cost effective design. The retaining wall system was assumed to be L-Shaped and restricted by the absence of a foundation toe. The structural elements of a standard type of retaining wall and an L-Shaped retaining wall is shown in Fig. 1 for comparison. It can be clearly seen from Fig. 1 that the absence of wall toe causes to reduce resisting wall forces that is acting according to the weight of the wall base. $\mathrm{H}$, represents the height of the wall stem; $h$, is the excavation depth and $D_{f}$, is the thickness
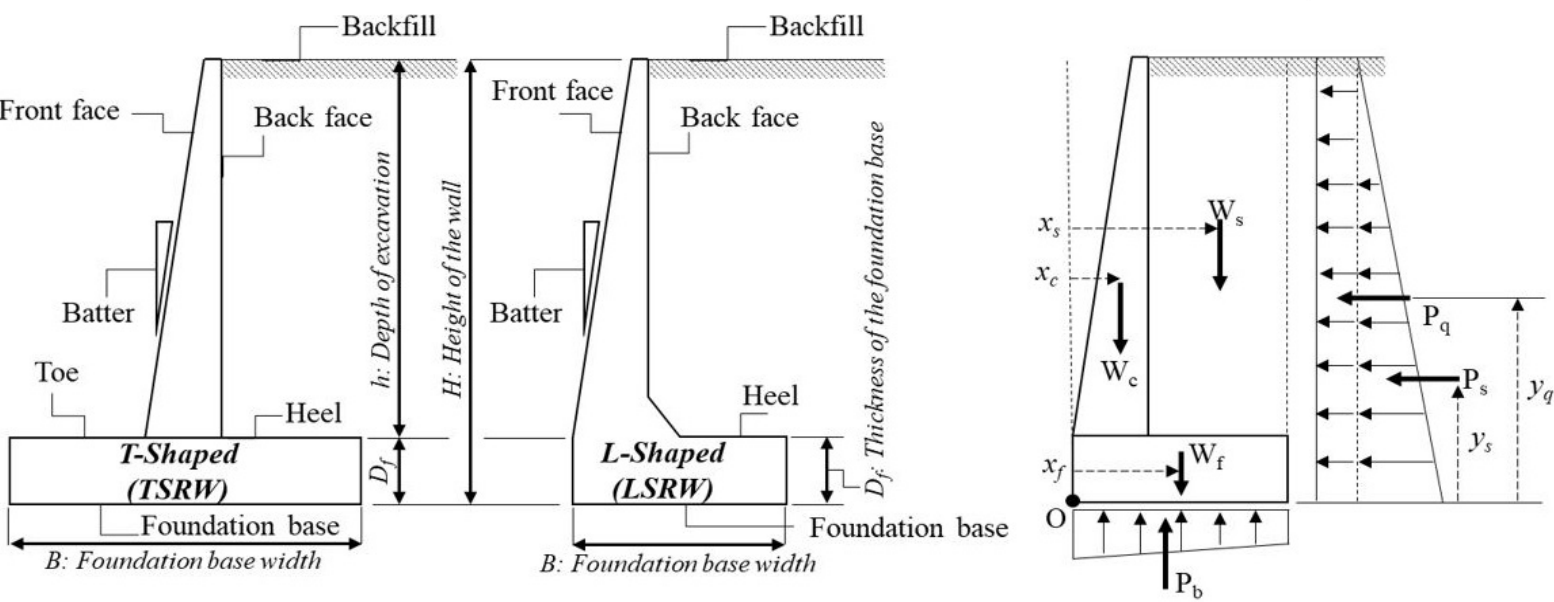

Figure 1. The structural parts of T-Shaped (TSRW) and L-Shaped (LSRW) reinforced concrete retaining walls 
of foundation base in Fig. 1. The generated pressures and related forces that are acting on the wall system and the distances to "O" turning point are given in Fig.1. $\mathrm{W}_{c}$ and $\mathrm{W}_{\mathrm{f}}$ is the weight of the wall stem and the foundation base and $x_{c}$ and $x_{f}$ is the horizontal distances of the mentioned weights to the $\mathrm{O}$ point respectively. $\mathrm{W}_{\mathrm{c}}$ and $\mathrm{W}_{\mathrm{f}}$ can be calculated by the multiplication of unit weight of concrete with the dimensions of the related sections according to plain strain condition. $\mathrm{W}_{\mathrm{s}}$ is the weight of the backfill soil retained on the heel of the foundation and xs is the lateral distance of this weight to $\mathrm{O}$ point. Ws can be calculated by the multiplication of the unit weight of the backfill soil $\left(\gamma_{s}\right.$ is the unit weight of the surrounding soil for this study) with the cross-section of backfill material that is retained on the heel of the wall. $\mathrm{P}_{\mathrm{b}}$ is the average value of foundation base pressures acting at the center of the gravity of foundation. $\mathrm{P}_{\mathrm{s}}$ is the lateral active soil force and $\mathrm{P}_{\mathrm{q}}$ is the lateral reflection of applied vertical surcharge loading. $y_{s}$ and $y_{q}$ represents the vertical distance of active soil force and lateral surcharge loading to the moment point $\mathrm{O}$. The achievement of lateral reflection of vertical loadings like surcharge or the calculation of lateral soil forces can be determined by the use of earth pressure theories that are proposed by several researchers $[13,14$, 15]. The Rankine earth pressure theory has been preferred to be used to calculate the lateral earth coefficients in this study because of its simple form containing only the effect of internal friction angle [14]. $\mathrm{K}_{\mathrm{a}}$ is the active lateral earth pressure coefficient that can be determined by a function of internal friction angle $\left(K_{a}=\tan ^{2}[45-\Phi / 2]\right)$. $\mathrm{K}_{\mathrm{a}}$ is used for the calculation of lateral value of affected active forces like Ps $=0.5 \mathrm{H}^{2} \gamma_{\mathrm{s}} \mathrm{K}_{\mathrm{a}}$. The term $\gamma_{\mathrm{s}}$ is used for representing the unit weight of the soil and it is evaluated as a variant of this study. $P_{q}$ is the lateral effect of the applied vertical infinite surcharge load like $q$ and it can be calculated by the use of $\mathrm{K}_{\mathrm{a}}\left(\mathrm{P}_{\mathrm{q}}=\mathrm{K}_{\mathrm{a}} \mathrm{q}\right)$. According to the calculated forces and moments, the wall structure has to be controlled against sliding, overturning stability safety and bearing capacity adequateness.

Lateral active forces can lead the wall to slide lengthwise of the base but on the contrary situation, the self-weight of the wall tries to resist to ensure stability. The division of the whole lateral resisting forces to the active forces has to be procured enough safety for sliding $\left(\mathrm{SF}_{\text {sliding }}\right)$. Besides sliding safety research, the existence of unbalanced active and passive forces in a structure causes to enforce the system to turn about its toe point (point "O" in Fig. 1) so another component of safety has born and it is called overturning $\left(\mathrm{SF}_{\text {overturning }}\right)$. The division of moments induced by resisting forces to the moments induced by sliding forces gives the degree of overturning safety. The third ingredient of safety is bearing capacity research. The bearing capacity failure has to be checked with the division of ultimate bearing pres- sure to the maximum mobilized soil pressure through the base foundation of the wall. The limits of ultimate bearing pressure of the base of the wall can be determined by the use of traditional equations of shallow foundation ultimate bearing capacity calculations $[16,17,1,3]$. The obtainment of the stability against the mentioned three stages allows to continue designing with regard to structural necessities. In the context of this research, all the design steps of the wall are controlled by the use of Flower Pollination Algorithm (FPA) with the analysis performed by Matlab Software. The algorithm is a population-based metaheuristic algorithm confirmed for its simple formulation and the effectiveness in terms of computational performance $[18,19]$. The logic of the Flower Pollination Algorithm is based on the evolutionary mechanism of biological flowering plant systems via pollination either biotic or biotic and developed by Yang (2012). Abiotic pollination happens at short distances so a local pollination mechanism is noted. Biotic pollination is eased by the pollinators like bees and butterflies that can travel long distances during their routine circulation. Herewith the method is utilized as a global pollination procedure. Flower constancy can be evaluated as the other significant property of the algorithm. Actually the pollinators have a direct tendency to choose certain flower species and ignore the other types [20]. By this way, the risks are decreased by pollinators and the intake of nectar is ensured. In addition to all these, four standard rules are described to determine the calculation of FPA.

1. The movement of the pollinators satisfies Levy flights.

2. Abiotic pollination is evaluated as a local pollination.

3. Flower constancy is equivalent to a reproduction probability and this situation is proportional to the similarity of the involved flowers.

4. The switch probability; $\mathrm{p}$ is a pre-fixed situation that is constant in $[0,1]$ and used to control the type of pollination either local or global.

Flower Pollination Algorithm consists a candidate solution vector $\mathrm{x}_{\mathrm{i}}$ that is characterized by a flower $\mathrm{i}$ in a population of $\mathrm{n}$ flowers. The flowers can present global or local pollination for the text population modelling. The global pollination algorithm regarding to flower constancy rule can be determined by Equation 1 .

$$
x_{i}^{t+1}=x_{i}^{t}+L\left(g^{*}-x_{i}^{t}\right)
$$

$x_{i}^{t}$ is the flower $\mathrm{i}$ at iteration $\mathrm{t}, \mathrm{g}$ is the best flower of all

the populations at iteration $\mathrm{t}$, and $\mathrm{L}$ is a Levy distribution. Besides Equation 1, the local pollination in relation to flower 
Table 1. The design variables of the wall system

\begin{tabular}{ccc}
\hline & Symbol & Description of parameter \\
\hline $\begin{array}{c}\text { Variables } \\
\text { interrelated } \\
\text { with } \\
\begin{array}{c}\text { Cross-section } \\
\text { dimension }\end{array}\end{array}$ & $X_{1}$ & Width of the heel \\
$\begin{array}{c}\text { Variables } \\
\text { interrelated } \\
\text { with reinforced } \\
\text { concrete design }\end{array}$ & $X_{3}$ & Thickness of the wall stem at the top \\
\hline
\end{tabular}

constancy rule can be modelled by Equation 2 .

$$
x_{i}^{t+1}=x_{i}^{t}+\varepsilon\left(x_{j}^{t}-x_{k}^{t}\right)
$$

In Equation 2, $x_{j}^{t}$ and $x_{k}^{t}$ represents the different flowers of a same population and $\varepsilon$ is drawn from a uniform distribution in $[0,1]$. This rule calculates the type of flower pollination is either local or global. If the random number drawn in $[0,1]$ is evaluated lower than $\mathrm{p}$, the global pollination is carried out. In the contrary case, local pollination is conducted. In order to perform cost-effective analysis of L-Shaped retaining walls with FPA it is necessary to specify the parameters of design and additionally it is essential to note the ranges of these parameters for obtaining the initial solutions. Six design variables $\left(\mathrm{X}_{1}, \mathrm{X}_{2}, \mathrm{X}_{3}, \mathrm{X}_{4}, \mathrm{X}_{5}, \mathrm{X}_{6}\right)$ selected to perform the analysis of L-Shaped walls (Table 1 ).

The design of the wall is started with the achievement of safety against the failure modes then if the satisfaction is ensured it becomes essential to identify the application of the requirements of reinforced concrete design. ACI 31805 code is used due to its prevalent usage. The ACI 318-05 code suggests to identify equivalent rectangular compressive stress distribution. By the equivalent compressive stress distribution, the moment capacity of the wall can be calculated and only the critical sections of the stem and base is checked. The constraints of design about strength of safety and dimensions are given in Table 2.
Table 2. The design constraints of solution

\begin{tabular}{|c|c|}
\hline Description & Description of parameter \\
\hline Safety for overturning & $\mathrm{g}_{1}(\mathrm{X}): \mathrm{FoS}_{\text {overturning,design }} \geq \mathrm{FoS}_{\text {overturning }}$ \\
\hline Safety for sliding & $\mathrm{g}_{2}(\mathrm{X}): \mathrm{FoS}_{\text {sliding,design }} \geq \mathrm{FoS}_{\text {sliding }}$ \\
\hline Safety for bearing capacity & $\mathrm{g}_{3}(\mathrm{X}): \mathrm{FoS}_{\text {bearingcapacity,design }} \geq \mathrm{FoS}_{\text {bearingcapacity }}$ \\
\hline Minimum bearing pressure $\left(q_{\operatorname{mir}}\right)$ & $\mathrm{g}_{4}(\mathrm{X}): \mathrm{q}_{\min } \geq 0$ \\
\hline $\begin{array}{l}\text { Flexural strength capacities of } \\
\text { critical sections }\left(M_{d}\right)\end{array}$ & $\mathrm{g}_{5-7}(X): M_{d} \geq M_{u}$ \\
\hline $\begin{array}{l}\text { Shear strength capacities of } \\
\text { critical sections }\left(V_{d}\right)\end{array}$ & $\mathrm{g}_{8-10}(X): V_{d} \geq V_{u}$ \\
\hline $\begin{array}{l}\text { Minimum reinforcement areas of } \\
\text { critical sections }\left(A_{\text {smir }}\right)\end{array}$ & $\mathrm{g}_{11-13}(\mathrm{X}): \mathrm{A}_{\mathrm{s}} \geq \mathrm{A}_{\mathrm{smin}}$ \\
\hline $\begin{array}{l}\text { Maximum reinforcement areas of } \\
\text { critical sections }\left(A_{\text {smax }}\right)\end{array}$ & $\mathrm{g}_{14-16}(\mathrm{X}): \mathrm{A}_{\mathrm{s}} \leq \mathrm{A}_{\mathrm{smax}}$ \\
\hline
\end{tabular}

The objective function is only consisted with the evaluation of material costs. Material costs are defined by the use of the costs per unit volume/weight. The mathematical formulation of the used objective function can be shown with Equation 3. In Eq. 3, unit cost of the concrete is $\mathrm{C}_{\text {con }}$ and its volume is $\mathrm{V}_{\text {con }}$ and the unit cost of the reinforcement is $\mathrm{C}_{\mathrm{st}}$ and its weight is $\mathrm{W}_{\text {st }}$.

$$
\min f_{x}=C_{c o n} \cdot V_{c o n}+C_{s t} \cdot W_{s t}
$$

The proposed algorithm is used with the mentioned restrictions and equations to acquire the optimal dimensions of the wall against the change of soil geotechnical properties.

\section{RESULTS AND DISCUSSION}

In the light of this mentioned study method, parametric analyses were conducted to control the effects of soil geotechnical properties on the optimal design of L-Shaped retaining walls. Arbitrarily selected cases have been used to model the cost and dimension optimization processes. The excavation depth was selected 3, 5, 7 and 9 meters and the surcharge load application were assumed to be $0,10,20 \mathrm{kPa}$ respectively for all the fictionalized cases. The variants of the soil geotechnical properties were assumed to be the internal friction angle and the unit we-

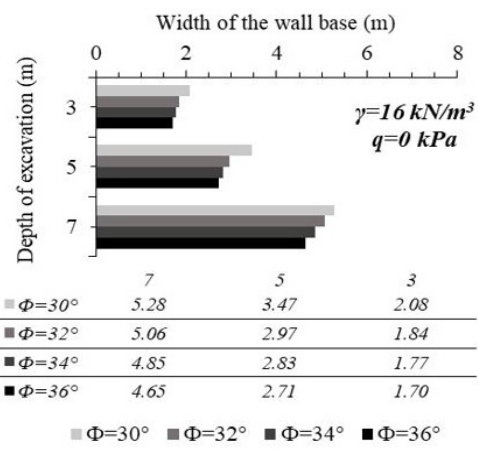

(a)

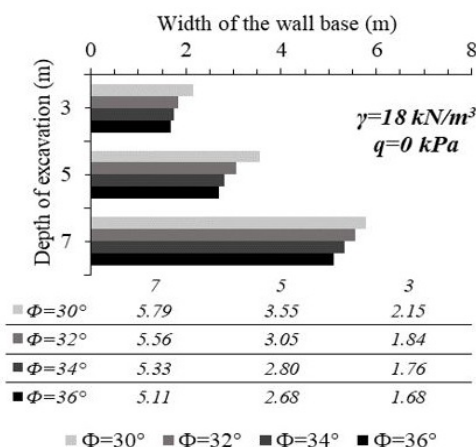

(b)

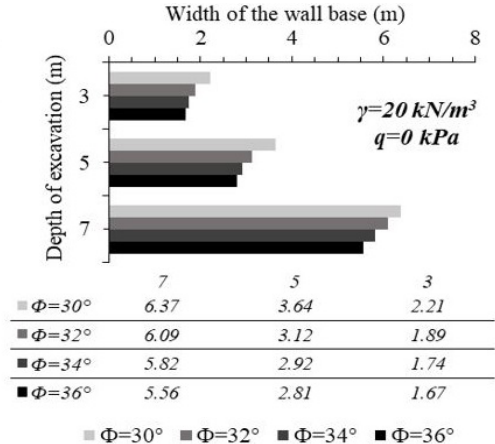

(c)

Figure 2. Change of wall base width against the unit weight of soil 


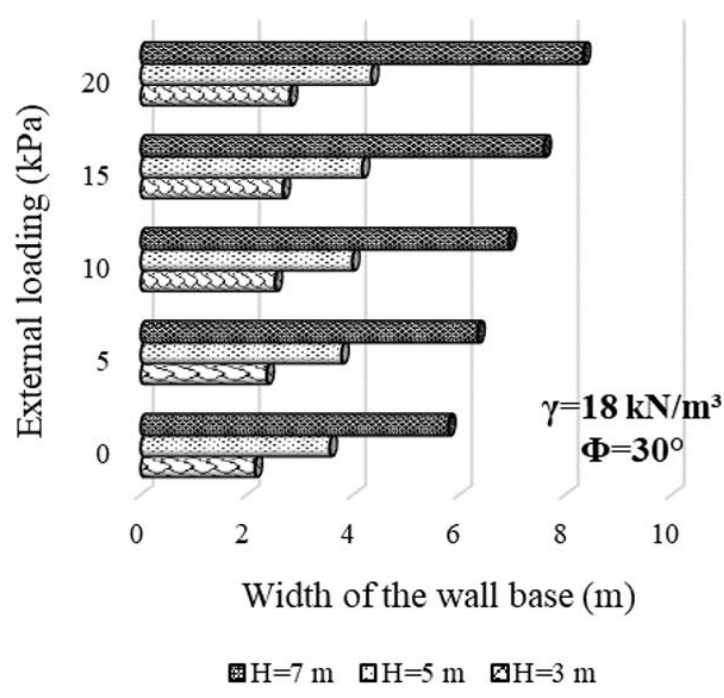

Figure 3. Change of wall base width against external loading

ight of the soil. The internal friction angle was selected 30 and $32^{\circ}$ to represent medium dense sandy soils and 34 and $36^{\circ}$ to represent dense sandy soils according to the given limits by Bowles (1988). Numerical analyses were performed to obtain the cost-effective sizing in relation with both geotechnical safety and structural necessities. Consequently, the optimization based design of LSRW is taken into consideration with the evaluations done by individual and dual interaction of parameters to designate the influence on optimum sizing. The optimization based design of LSRW is investigated with the performed 105000 analyses by Matlab software. The design has been controlled by evaluating the changes happened for the width and thickness of the foundation base. The wall height is also taken into consideration with the sum of excavation depth and foundation base thickness. In Fig. 2 , the change of wall base width is identified for different soil unit weights in relation with the change of internal friction angle. All graphs were illustrated for three different excavation depths (3, 5, 7 meters). The absence of external surcharge load is assumed to be applied in whole selected cases. It has to be noted that the vertical and ho-

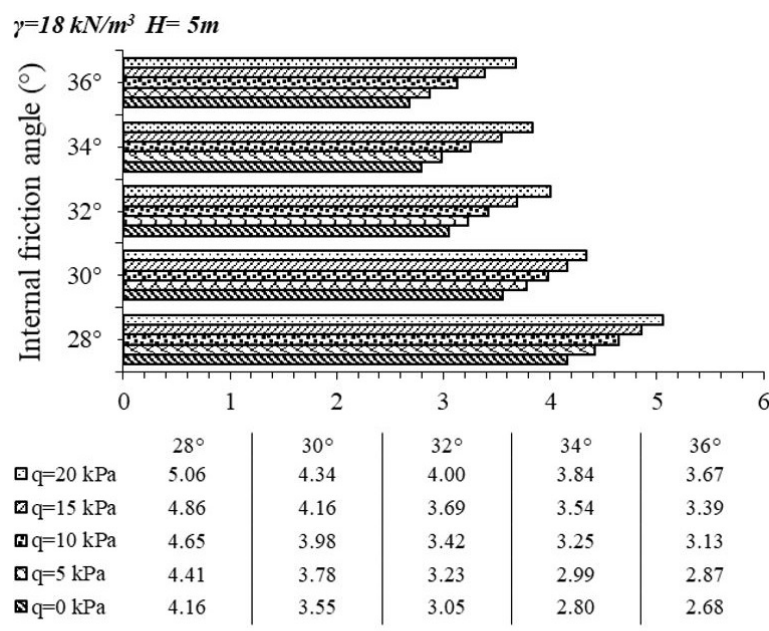

Width of the wall base (m)

$$
\nabla \mathrm{q}=20 \mathrm{kPa} \quad \square \mathrm{q}=15 \mathrm{kPa} \quad \mathbf{\mathrm { E } q}=10 \mathrm{kPa} \quad \square \mathrm{q}=5 \mathrm{kPa} \quad \mathbf{\mathbb { q }}=0 \mathrm{kPa}
$$

Figure 5. Change of wall base width against external loading and friction angle

rizontal axes of the illustration are selected as the same to ease comparison.

The unit weight of soil has been selected $16 \mathrm{kN} / \mathrm{m}^{3}, 18$ $\mathrm{kN} / \mathrm{m}^{3}$ and $20 \mathrm{kN} / \mathrm{m}^{3}$ in Fig. $2 \mathrm{a}, \mathrm{b}$ and c respectively. As a general evaluation, the comparison of Fig. $2 \mathrm{a}$, b and c shows that the increase of unit weight of soil leads to enlarge the width of soil base. This condition is especially significant for the cases that are identified for deeper excavation depths. The increase of soil unit weight from 16 to $20 \mathrm{kN} / \mathrm{m}^{3}$, for 3 meters excavation depth, leads the design to enlarge the foundation base width \%6. Besides this if the excavation depth is increased to 7 meters, the increment of soil unit weight leads the design to enlarge the foundation base width \%20 for all the internal friction angle assumptions. The evaluation of the increase of excavation depth from 3 meters to 7 meters, by the consideration of same soil conditions, leads the foundation base to be bigger than $\% 150$ for $16 \mathrm{kN} / \mathrm{m}^{3}$ soil unit weight, bigger than $\% 170$ for $18 \mathrm{kN} / \mathrm{m}^{3}$ soil unit weight and bigger than $\% 190$ for $20 \mathrm{kN} / \mathrm{m}^{3}$ soil unit weight approxi-

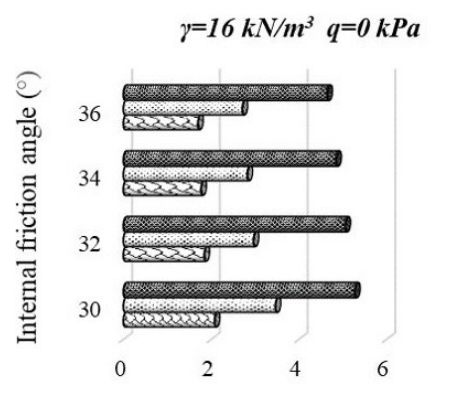

Width of the wall base (m) $\boxplus \mathrm{H}=7 \mathrm{~m} \quad \square \mathrm{H}=5 \mathrm{~m} \quad \square \mathrm{H}=3 \mathrm{~m}$

(a)

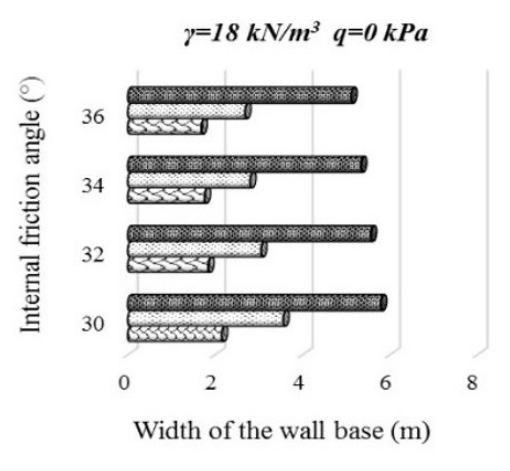

$\bullet \mathrm{H}=7 \mathrm{~m} \quad \square \mathrm{H}=5 \mathrm{~m} \quad \boldsymbol{\nabla H}=3 \mathrm{~m}$

(b)

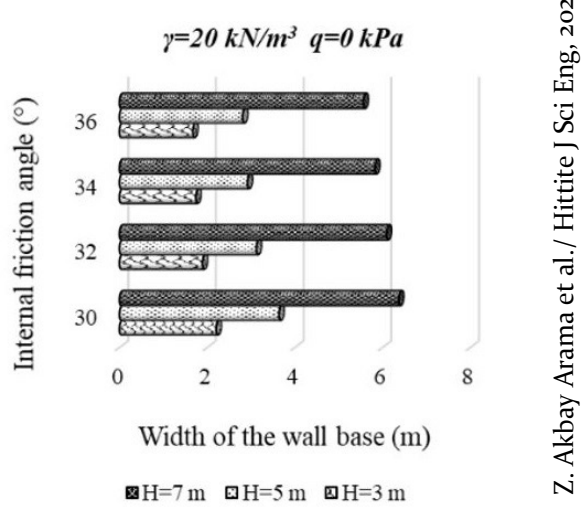

(c)

Figure 4. Change of wall base width against the internal friction angle 


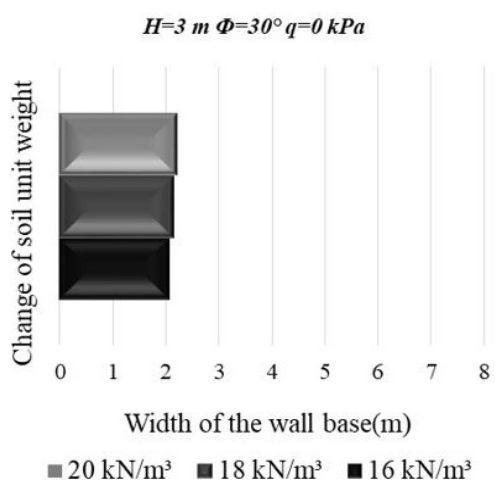

(a)

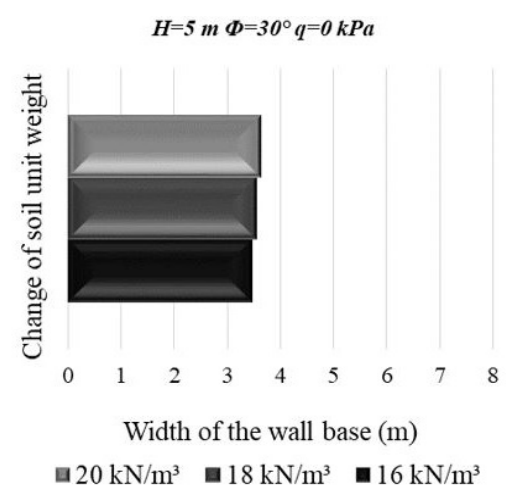

(b)

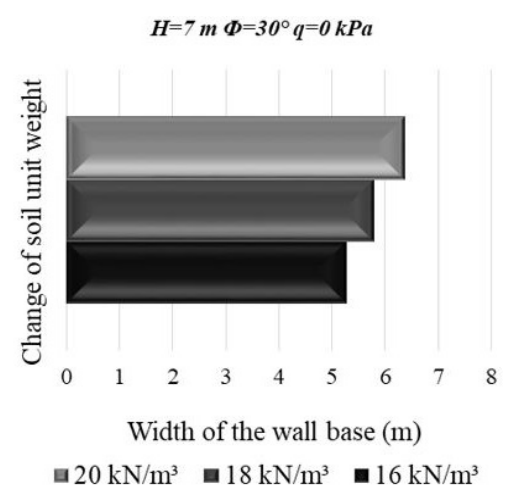

(c)

Figure 6. Change of wall base width against the change of soil unit weight and excavation depth

mately. In addition to these, it can be said that the increase of internal friction angle tends to decrease the width of foundation base related to the increment degree. Fig. 3 shows the change of wall foundation base width against different external surcharge loading conditions. The absence of surcharge loading and 5, 10, 15, $20 \mathrm{kPa}$ loading situations has been investigated as a case within the concern of this paper. The internal friction angle was $30^{\circ}$ and the unit weight of soil was $18 \mathrm{kN} / \mathrm{m}^{3}$ for the selected reference case. The differentiation of wall base width was also investigated in relation with the change of excavation depth. It can be seen from Fig. 3 that the wider base width causes the bigger external loading. The reference case was selected the absence of an external loading situation for comparisons. In a situation which the excavation depth is assumed to be 3 meters, the increase of the external load from zero to $5,10,15,20 \mathrm{kPa}$ leads the base width to enlarge 10\%, 17\%, 24\%, 30\% respectively. If the excavation depth was assumed to be 7 meters, the increase of external load causes to widen the base width $\% 9, \% 19, \% 31$, and $\% 43$ as regard to the reference case. As a result, it is clear to say that the degree of the surcharge effect is raised in accordance with the depth of excavation.

Fig. 4 is illustrated to define a clear relationship of the effects of internal friction change on the design of the retaining wall system. The absence of the surcharge was assumed and the difference of soil unit weight was also shown. The increase of soil internal friction angle decreases the width of the wall base for the cases evaluated. But the maximum dimension change between the maximum and minimum values of envisaged internal friction angles were not bigger than \%25. Fig. 4 a, b and c is drawn for different soil unit weights to make dual interacted evaluations between variants of the analyses. Depending on, it will be proper to say that, excavation depth is the most influencer parameter of design process. The change of internal friction angle is almost more effective than the change of unit weight of soil for L-Shaped walls especially in the cases assumed in this study. In addition, it is necessary to say that the envisaged numerical difference between the selected parameters are also important to interpret the interaction behavior through the obtained variants.

Fig. 5 shows a detailed relationship between the effects of external load change related to different internal friction angles. The unit weight of the soil is assumed to be same with Fig. $4\left(18 \mathrm{kN} / \mathrm{m}^{3}\right)$ and the excavation depth is selected 5 meters as a constant value. It can probably seen from the Fig. 5 that the increase of external loading is perceived bigger by dense sands in terms of the dimension change. In such a case that, if the relative base width increase difference between upper and lower bounds of the surcharge is evaluated, the dimension change of the wall happens approximately $\%$ 10 bigger than the loose sand condition for dense sand.

In Fig. 6, the effect of the unit weight change of the soil on the wall base width is investigated based on different excavation depths. The relative width differentiation between the upper and lower limits of soil unit weight for 3 meters excavation depth seems not to be important vis-a-vis the changes happened for 7 meters excavation depth. Correspondingly, it can be said that the influence ratio of the soil unit weight increases depending on the increase of the excavation depth.

Fig. 7 considers the subject from a different angle by assuming the foundation base thickness as an affected dimension by the variants of the analyses. Fig. 7 is an integrated illustration of the dual interaction of variants. The change of soil unit weight is drawn with the use of subdivisions of the figure and also the change of internal friction change and the deepening of the excavation depth is taken into consideration. The absence of the surcharge load is assumed for all the cases. The thickness of the foundation base was unaffected till 5 meter excavation depth and $36^{\circ}$ internal friction angle. At 5 meters excavation depth, the increase of internal friction angle to $36^{\circ}$ was caused to increase the thickness of the base at a rate of $\% 33$. The increment of the excavation depth has been increased the thickness of the base approximately \%100 for dense sandy soils. 


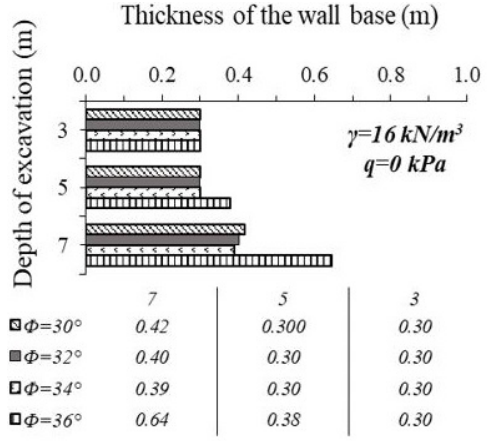

$\triangle \Phi=30^{\circ} \square \Phi=32^{\circ} \square \Phi=34^{\circ} \square \Phi=36^{\circ}$

(a)

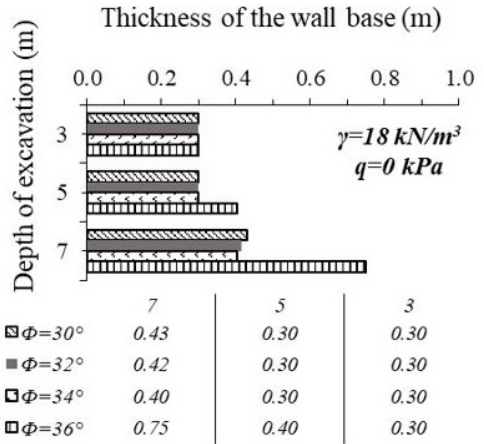

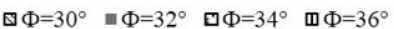

(b)

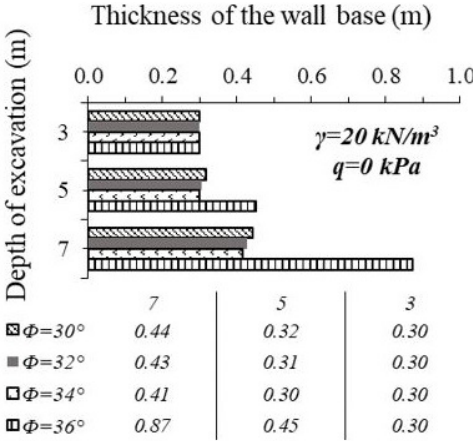

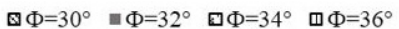

(c)

Figure 7. Change of wall base thickness against the change of soil unit weight $(\mathrm{q}=0 \mathrm{kPa})$

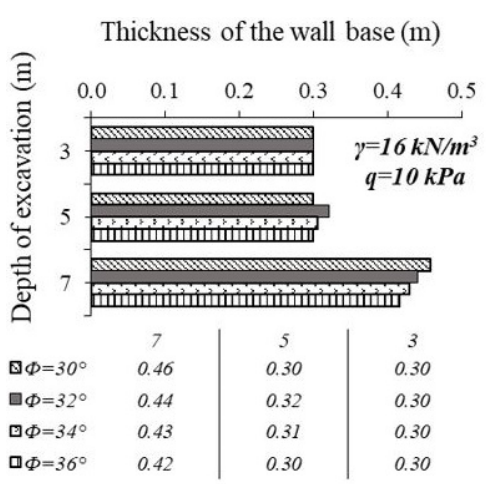

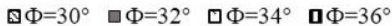

(a)

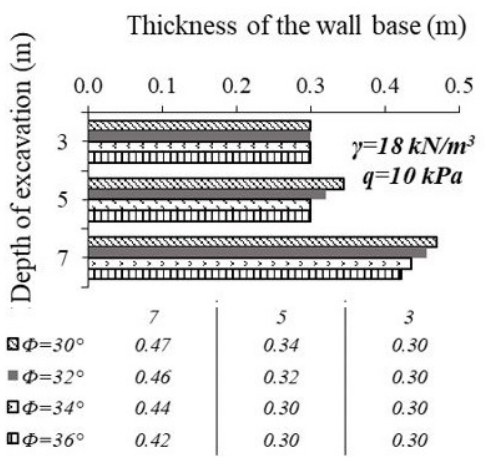

ब $\Phi=30^{\circ}$ घ $\Phi=32^{\circ}$ 曰 $\Phi=34^{\circ}$ Ф $\Phi=36^{\circ}$

(b)

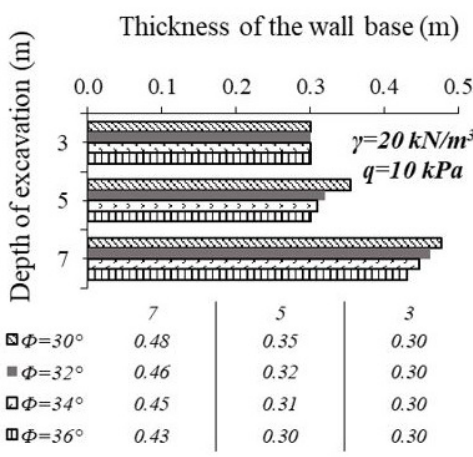

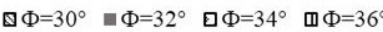

(c)

Figure 8. Change of wall base thickness against the change of soil unit weight $(\mathrm{q}=10 \mathrm{kPa})$

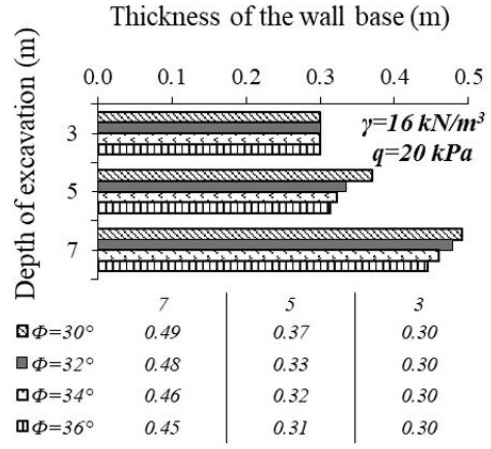

凶 $\Phi=30^{\circ} \square \Phi=32^{\circ} \square \Phi=34^{\circ}$ 凹 $\Phi=36^{\circ}$

(a)

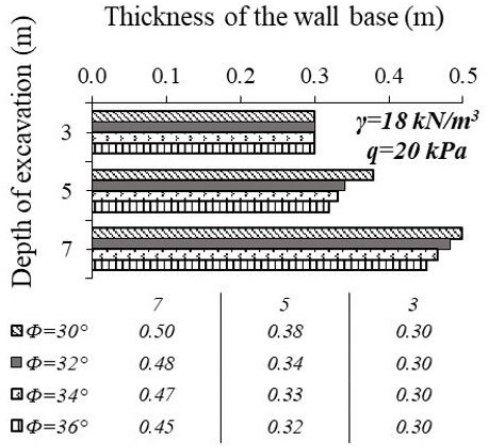

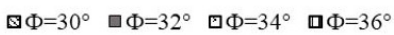

(b)

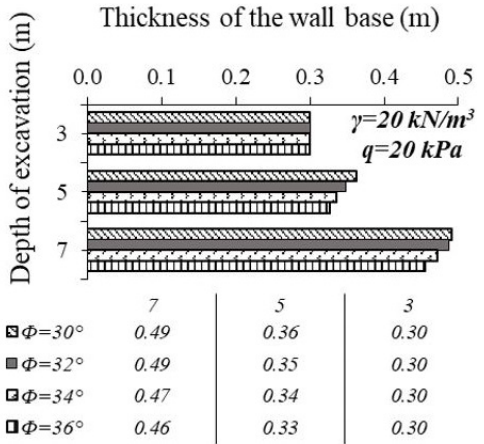

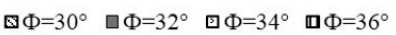

(c)

Figure 9. Change of wall base thickness against the change of soil unit weight ( $q=20 \mathrm{kPa})$

In Fig. 8, the change of foundation base thickness is given based on the increase of external load to $10 \mathrm{kPa}$. The subdivisions of the figure are drawn to show the change of soil unit weight and internal friction angle and excavation depth is also taken into account. Comparison of Fig. 7 and Fig. 8 shows that the increase of external load directly raises the thickness of the wall base nearly at a rate of $\% 33$. On the other hand, the change of soil unit weight under the condition that the increase of surcharge is actual, had not got an influence on the thickness of the base. A similar behavior trend is seen in Fig. 8 with Fig. 7 and the increasing of the excavation depth causes to increase the thickness of the foundation base. But differentiated from Fig. 7 that the effect of the increase of internal friction angle had affected the thickness of the base for all selected cases.

Fig. 9 represents the change of base thickness with the increase of external load to $20 \mathrm{kPa}$ value. Same subdivisions 
are prepared with the same parameters in Fig. 7 and Fig. 8 for to ease comparison. The change of soil unit weight has no effect on the base thickness dimension of the wall. Besides this, if the application of external load to an envisaged maximum value was occurred ( $10 \mathrm{kPa}$ for this study), the thickness of the wall base was not changed. Therefore, it can be said that the dominant effect of the change of the design parameters on the sizing of the wall is reflected to the width of the foundation base.

\section{CONCLUSION}

In this study, huge number of comparative parametrical analyses were conducted to achieve the effects of soil geotechnical properties on the cost effective sizing of L-shaped reinforced concrete retaining walls. The studies about the design of L-shaped retaining walls are very limited in the literature so this study is special for the achievement of design limits of restricted type of walls. The width and thickness of the retaining wall were assumed to be the affected dimensions of the wall structure. The parametrical analyses were performed by the use of Matlab software Flower Pollination Algorithm. The results of the analyses show that:

- The change of excavation depth is the major influencer factor of sizing. The increase of the excavation depth raises the wall dimensions directly proportional.

- Internal friction angle is the most important soil geotechnical parameter for the design of retaining walls that are embedded in sandy soils. The increase of internal friction angle leads to narrow the width of the base. In addition to these, the increase of the friction angle of sandy soils leads to decrease the thickness of the base after a boundary excavation depth (this depth is 7 meters for the cases analyzed in this study).

- The increase of surcharge is also an effective external factor in sizing because the increase of surcharge causes enlarging the base. This increase ratio increases proportional to the excavation depth. The increase of external loading is perceived bigger by dense sand in terms of the dimension change. In addition to these, the raise of surcharge increases the thickness of the base nearly one third of the dimension that is acquired in the case which the absence of the external load is assumed.

- The increase of the unit weight of the soil enlarges the foundation base width, but has no effect on the thickness. - The thickness of the wall base is not influenced by the change of variants until a reference excavation depth is reached.

- The results of the optimization analyses show that L-Shaped restricted walls are not proper to resist lateral earth pressures which are caused because of bigger than 9 meters deep excavations. Because there could not be obtained a proper design due to the lack of technical ade- quateness (either geotechnical or static design safety requirements) within the limits of defined design variables. - It has to be noted that these mentioned results are acquired based on the fictionalized cases within this study. According to this situation, the change of the assumptions of the cases will affect the influence ratios of the design variables.

\section{REFERENCES}

1. Bowles JE. Foundation analysis and design, fifth ed. McGraw-Hill, New York, 1988.

2. Das BM, Sobhan K. Principles of geotechnical engineering, eighth ed. Cengage Learning, Stamford, 2010.

3. Yıldırım S. Zemin incelemesi ve temel tasarımı, Third ed. Birsen Yayınevi, İstanbul, 2002.

4. Azizi F. Applied Analyses in geotechnics, first ed. E \& FN Spon, London, 2000.

5. Sasidhar T, Neeraja D, Sudhindra VSM. Application of genetic algorithm technique for optimizing design of reinforced concrete retaining wall. International Journal of Civil Engineering and Technology 8(5) (2017) 999-1007.

6. Rouili A. Design of Rigid L- Shaped Retaining Walls. World Academy of Science, Engineering and Technology, International Journal of Civil Science and Engineering 7(12) (2013) 908-911.

7. Ceranic B, Fryer C, Baines RW. An application of simulated annealing to the optimum design of reinforced concrete retaining structures. Computers \& Structures 79(17) (2001) 1569-1581.

8. Ahmadi-Nedushan B, Varaee H. Optimal Design of Reinforced Concrete Retaining Walls using a Swarm Intelligence Technique. in Topping BHV, Tsompanakis Y (Eds). Paper presented at the first International Conference on Soft Computing Technology in Civil, Structural and Environmental Engineering, Stirlingshire, January 2009.

9. Camp CV, Akin A. Design of Retaining Walls Using Big Bang-Big Crunch Optimization. Journal of Structural Engineering 138(3) (2012) 438-448.

10. Kaveh A, Kalateh-Ahani M, Fahimi-Farzam M. Constructability optimal design of reinforced concrete retaining walls using a multiobjective genetic algorithm, Structural Engineering and Mechanics 47(2) (2013) 227-245.

11. Bekdas G, Temur R. Grey Wolf Optimizer for Optimum Design of Reinforced Concrete Cantilever Retaining Walls. Paper presented at International Conference of Numerical Analysis and Applied Mathematics (ICNAAM), Thessaloniki, 25-30 September 2017.

12. Uray E, Çarbaş S, Erkan İH, Tan Ö. Parametric investigation for discrete optimum design of a cantilever retaining wall. Challenge Journal of Structural Mechanics 5(3) (2019) 108-120.

13. Coulomb CA. Essai sur une application des regles des maximis et minimis a quelques problemes de statique relatifs a l'artitecture. De l'Imprimerie Royale, Paris, 1776.

14. Rankine WJM. On the stability of loose earth, The Royal Society, London, 1857.

15. Terzaghi K. General wedge theory of earth pressure, Transactions, ASCE. 106 (1941) 68-97.

16. Dembicki E, Chi T, System analysis in calculation of cantilever retaining walls. International Journal for Numerical and Analytical Methods in Geomechanics 13(6) (1989) 599-610.

17. Powrie W. Limit equilibrium analysis of embedded retaining walls. Geotechnique 46(4) (1996) 709-723. 
18. Alyasseri ZAA, Khader AT, Al-Betar MA, Awadallah MA, Yang XS Variants of the flower pollination algorithm: a review. Studies in Computational Intelligence 744 (2018) 91-118.

19. Mergos PE, Mantoglou F. Optimum design of reinforced concrete retaining walls with the flower pollination algorithm. Structural and Multidisciplinary Optimization 61 (2020) 575-585.
Yang XS. Flower Pollination Algorithm for Global Optimization. In: Durand-Lose J., Jonoska N. (eds) Unconventional Computation and Natural Computation (UCNC 2012), Lecture Notes in Computer Science 7445 (2012) 240-249.

21. ACI 318. Building Code Requirements for Structural Concrete and Commentary. ACI Committee, 2014 